\title{
If a student thinks, "I'm not a math person", do preservice teachers notice?
}

\author{
Helene Rieche ${ }^{1^{*}}$, Timo Leuders ${ }^{2}$, and Alexander Renk ${ }^{1}$ \\ ${ }^{1}$ Department of Educational and Developmental Psychology, University of Freiburg, Freiburg, Germany \\ 2 Institute of Mathematics Education, University of Education Freiburg, Freiburg, Germany \\ For correspondence: helene.rieche@psychologie.uni-freiburg.de
}

\begin{abstract}
Students' beliefs that mathematical abilities are fixed can cause long-standing problems with motivation and learning. Hence, teachers should notice such problematic beliefs about identity among their students and handle them adequately. We used written descriptions of classroom situations to determine whether preservice mathematics teachers $(n=80)$ noticed fixed beliefs about mathematical abilities and whether they had strategies for dealing with them. The qualitative data were coded and transformed into a score for noticing. We found that most of the preservice teachers did not notice problematic beliefs. Thereby, preservice teachers who believed that mathematical abilities are malleable were more likely to notice fixed beliefs among students. When describing beliefs, few participants referred to theoretical concepts. Hardly any preservice teachers suggested strategies for handling students' beliefs. However, the strategies that were suggested mostly corresponded with findings from educational research. Our study provides first evidence that preservice teachers' abilities to notice and handle belief-related problems may be insufficient. We discuss implications for teacher education as well as directions for future research.
\end{abstract}

Keywords: beliefs, identity, teacher noticing, professional vision, teacher education

\section{Introduction}

During the past decades, numerous studies analyzed students' beliefs about their mathematical abilities and how such beliefs affect their learning (e.g., Blackwell, Trzesniewski, \& Dweck, 2007; OECD, 2013; Rattan, Good, \& Dweck, 2012; Tuijl \& Molen, 2015). Especially with respect to the subject of mathematics, people tend to believe that you are either a "math person" - or you are not. In other words, mathematical abilities are frequently seen as fixed (Boaler, 2015; Jonsson, Beach, Korp, \& Erlandson, 2012). Having such a fixed mindset has several negative consequences such as low selfregulation or a weak commitment to the subject (Blackwell et al., 2007; Burkley, Parker, Paul Stermer, \& Burkley, 2010; Burnette, O’Boyle, VanEpps, Pollack, \& Finkel, 2013; Wood \& Bandura, 1989). Fortunately, such dysfunctional beliefs can be changed (Burnette, Russell, Hoyt, Orvidas, \& Widman, 2017; Mueller \& Dweck, 1998; Rattan et al., 2012; Schmidt, Shumow, \& Kackar-Cam, 2017; Yeager \& Walton, 2011). Hence, teachers should be aware of student beliefs and possible interventions in order to react adequately when students reveal problematic beliefs.

Teacher knowledge and skills are frequently conceived as professional vision, in the sense of being able to combine knowledge and practice in classroom situations (van Es \& Sherin, 2002). However, there is little empirical evidence concerning teachers' professional vision when they encounter students' beliefs. Given the substantial impact that ability beliefs have on students' learning, we explored preservice teachers' professional vision with respect to noticing students' beliefs about abilities, describing them professionally, and developing suitable strategies. We also investigated whether preservice teachers' noticing was related to their own intuitive theories about mathematical abilities. 
Teachers' professional vision regarding student beliefs.

Professional vision refers to the ability to identify and reason about relevant aspects in classroom situations based on theoretical concepts (Sherin \& van Es, 2009). Hence, professional vision describes how teachers put their knowledge into action. Van Es and Sherin (2002) initially defined two components of professional vision: noticing as the ability to perceive relevant aspects, and knowledgebased reasoning as the ability to describe, explain and interpret these relevant aspects. Recently, a third component has been added: decision-making as the ability to decide how to respond to the situation (Blömeke, Gustafsson, \& Shavelson, 2015; Jacobs, Lamb, \& Philipp, 2010; Kaiser, Busse, Hoth, König, \& Blömeke, 2015). As these skills should be developed during teacher education, the present article focuses on preservice teachers.

When relating the three steps - noticing, reasoning, and decision-making - to a classroom situation in which a student exhibits a fixed belief about abilities, three questions arise: (1) Do preservice teachers notice the belief and identify it as important? (2) How do they reason about the belief? (3) What decisions do preservice teachers make? In the following, we will take a closer look at each step.

The first component of professional vision is the ability to identify important aspects or events in the classroom (van Es \& Sherin, 2002). Noticing is seen as a prerequisite for teacher acting, as only those classroom features that grab teachers' attention will be dealt with. Accordingly, preservice teachers must first notice beliefs among their students to handle them adequately. Beliefs such as "not being a math person" can be defined as dysfunctional beliefs, as they impair students' engagement in the mathematics classroom (see research on identity; e.g., Grootenboer, Smith, \& Lowrie, 2006). Compared to temporary problems that arise from the mathematical content, such belief-related problems may be of a long-term nature. We therefore view students' ability beliefs as important aspects that teachers should notice and react to. In general, noticing seems to develop with growing practical experience (Stahnke, Schueler, \& Roesken-Winter, 2016). For example, a recent study that used a video-based measurement of teachers' perception revealed that experienced teachers' noticing tends to be more accurate and holistic than inexperienced teachers' noticing (König \& Kramer, 2016). Hence, it can be assumed that the ability to notice student beliefs is still on a lower level among preservice teachers, but improves during their education. While numerous studies examined how teachers notice students' mathematical cognition (e.g., Cooper, 2009; Lee \& Cross Francis, 2017; Pankow et al., 2016; Teuscher, Leatham, \& Peterson, 2017), fewer studies have focused on social aspects. One social aspect that was addressed by these studies is 'noticing for equity', which describes how teachers attend to signs of inequity such as issues of status, identity, or classroom participation (Hand, 2012; Louie, 2018; Wager, 2014). For instance, Kalinec-Craig (2017) used phenomenological case studies to investigate how preservice mathematics teachers attended to students who had a low status in the class. The underlying assumption of such studies is that inequity will continuously impair some students' learning, regardless of their actual cognitive skills or the mathematical content. Believing that one can divide between people who can and people who cannot do mathematics - as done with a fixed mindset - closely connects to inequity in the classroom. Thus, we contribute to the field of research by assessing how preservice teachers notice beliefs about the nature of mathematical abilities.

The second component of professional vision is the ability to reason about the noticed event by mapping it to theoretical concepts (van Es \& Sherin, 2002). Seidel and Stürmer (2014) developed a standardized video tool to assess professional vision. In three consecutive studies with preservice teachers, they investigated different aspects of knowledge-based reasoning and emphasized that profound descriptions of the noticed classroom event are an important indicator for this ability. However, inexperienced teachers tend to provide superficial descriptions instead of profound and knowledge-based descriptions of a situation (Carter, Cushing, Sabers, Stein, \& Berliner, 1988; Jacobs et al., 2010; Seidel \& Prenzel, 2007). Hence, we expected the quality of descriptions to be rather low 
among preservice teachers, as we analyzed how they described student beliefs. In this context, the question arises as to what knowledge may be suitable for reasoning about ability beliefs. A review of the literature shows that general pedagogical knowledge may apply, as does mathematics-specific knowledge. Pedagogical knowledge is seen as one important part of teacher knowledge (Shulman, 1986), and it includes knowledge about learners' motivational processes (Voss, Kunter, \& Baumert, 2011). Four examples illustrate which concepts about learners' motivation may be useful when facing students' beliefs about their identity and their abilities: (1) Intuitive theories about intelligence (Dweck, 2000) describe what people believe about the stability of cognitive abilities. Some people see abilities as fixed (entity theory), others see them as changeable (incremental theory). (2) Self-concept (Shavelson, Hubner, \& Stanton, 1976) describes peoples' perceptions of and beliefs about themselves, including beliefs about their abilities. (3) Self-efficacy (Bandura, 1993) describes peoples' beliefs in their ability to handle tasks and to overcome challenges in specific situations. (4) Attribution theory (Kelley, 1973) describes how people explain causes of specific events or outcomes. These attributions are related to beliefs about how ability as an internal, stable factor leads to success or failure. Note that all four theoretical models refer to learners' beliefs about their abilities. Teachers' knowledge about teaching a specific subject is known as 'pedagogical content knowledge' (Shulman, 1986) and includes knowledge about the individual learners and their subject-specific difficulties (Depaepe, Verschaffel, \& Kelchtermans, 2013). With regard to beliefs about mathematical abilities, researchers have partly applied general psychological concepts to mathematics, and partly looked at belief-related aspects that specifically apply to mathematics. Four examples illustrate which subject-specific concepts may be useful when facing students' ability beliefs in mathematics: (1) Mathematics self-concept (Marsh, 1990) describes peoples' perceptions and beliefs about themselves in mathematics, including those about their mathematical abilities. (2) Research about mathematics-specific beliefs among students was inspired by Schoenfeld (1988), who found that seeing mathematical ability as innate was typical in mathematics. (3) Di Martino and Zan (2010) suggest a model for students' attitudes towards mathematics, including beliefs about mathematics as well as beliefs about one's mathematical abilities. (4) Mathematics anxiety is defined as an irrational dread of mathematics and is associated with low confidence in the ability to do mathematics (Furner \& Berman, 2003). All four approaches address learners' beliefs about their mathematical abilities and their self-identity that they are 'not a math person'.

The third component of teachers' professional vision is the ability to decide about adequate actions in classroom situations (Blömeke, Gustafsson, et al., 2015). Decision-making captures teachers' intentions to act and is thereby connected to their observable behavior in the classroom. In addition, teachers' decision-making was found to be related to student learning (Kersting, Givvin, Thompson, Santagata, \& Stigler, 2012). Similar to the development of noticing and reasoning, teachers' decisionmaking seems to improve with growing experience. For instance, Jacobs and colleagues (2010) presented video clips as well as students' written answers to novice and expert teachers, and asked how they would respond to the students' mathematical thinking. The experienced teachers' responses were of higher quality, in a sense that the suggested strategies were based on evidence from the specific situation and consistent with research on mathematical development. With regard to student beliefs, the question arises as to what constitutes an adequate teacher action. We suggest that the stance teachers take may determine their actions. For instance, when adopting an attribution stance, teachers might try to change the student's dysfunctional patterns of attributions (Borkowski, Weyhing, \& Carr, 1988); from a self-concept stance, teachers might focus on enhancing the student's self-concept (Marsh \& Craven, 1997). When teachers focus on intuitive theories, their interventions might mainly emphasize the development of an incremental theory about abilities (Yeager \& Walton, 2011). Consequently, the preservice teacher's response depends on his or her knowledge about the concepts mentioned above. Depending on the theoretical approach, there are various possibilities for intervening adequately when a student reveals problematic beliefs about abilities. 
Relation between teachers' noticing and their beliefs about mathematical abilities.

Teachers' beliefs have a substantial impact on their noticing, reasoning, and decision-making (e.g., Blömeke, Hoth, et al., 2015; Lee \& Cross Francis, 2017; Meschede, Fiebranz, Möller, \& Steffensky, 2017; Saylan, Armagan, \& Bektas, 2016). With our focus on ability beliefs, we will more closely investigate how teachers' beliefs about abilities - namely, their intuitive theories about the stability of mathematical abilities - may affect their professional vision. These theories are found to be associated with preservice and in-service teachers' noticing of critical instances in mathematics lessons (Dreher \& Kuntze, 2014) and with the perception and evaluation of instructional situations (Kuntze, 2012). For instance, teachers following an incremental theory prefer argumentative interaction in the classroom to teacher-centered instruction. Others have found that teachers' intuitive theories influence their causal attributions about student achievement as well as their judgments about students' abilities (Butler, 2000; Rattan et al., 2012). Teacher students with an entity theory tend to attribute students' poor performances to their low abilities (Rattan et al., 2012). These findings show that holding an entity theory can lead to an "entity" perception and interpretation of students' difficulties during mathematics lessons. From this point of view, students are considered by the teacher to fail due to their lack of ability, not because of other reasons such as their problematic beliefs. Hence, we assume that preservice teachers with an entity theory tend to notice the students' low abilities when asked about their difficulties; preservice teachers with an incremental theory tend to notice the students' underlying beliefs. In our study, we tested the relation between the preservice teachers' intuitive theories about mathematical abilities and their noticing of student beliefs.

The present study.

In general, investigating teachers' professional vision with respect to student beliefs adds to our understanding of how teachers act when they face problematic beliefs in their mathematics lessons. The purpose of this study was to analyze preservice teachers' skills of noticing, reasoning, and decision-making in cases of students who believe that mathematical abilities are a fixed entity. We focused on preservice teachers and expected practical experience to have a positive impact on the level of professional vision. Hence, we included preservice teachers with different levels of experience in our sample and assessed their practical experience as well as their academic progress. Specifically, we addressed the following research questions:

1. Do preservice teachers notice student beliefs about mathematical abilities?

2. To what extent do preservice teachers refer to theoretical concepts when describing student beliefs?

3. What kind of strategies do preservice teachers employ when handling student beliefs about mathematical abilities?

4. Does preservice teachers' noticing of student beliefs relate to their academic progress or to their practical experience?

5. Does preservice teachers' noticing of student beliefs relate to their intuitive theories about mathematical abilities?

\section{Methods}

Participants.

The sample consisted of 80 preservice mathematics teachers ( $68 \%$ female, age $M=22.7, S D=2.65$ ) from German universities. The majority $(80 \%)$ were future teachers on the secondary level, while $15 \%$ aimed to teach at primary schools, and $5 \%$ were pursuing a job in special needs schools. The school type did not affect the outcome variable $(p=.34)$. Most of the participants had little practical experience in the classroom (6 months or less: 79\%; 7-12 months: $14 \%$; more than 12 months: 7\%). Their academic progress (i.e., the time being enrolled in a mathematics teacher education program) was on average six semesters $(M=6.01, S D=2.88$; $\operatorname{Min}=1.00, \operatorname{Max}=12.00)$, which is equivalent to three years. We recruited the participants through university departments of mathematics education. 
All participants took part voluntarily and received a voucher over $7 €$ for participating. Each participant read a consent document about the procedures and data protection, and provided informed consent by clicking on a "continue"-button. All were aware of taking part in research. The data were collected and analyzed anonymously.

\section{Material.}

Vignettes. We selected written vignettes for measuring professional vision. According to the 'approximations of practice' (Grossman et al., 2009), written vignettes are less authentic than, for instance, videos. However, videos have some disadvantages that can be outweighed by the usage of written vignettes: On one hand, the information in videos is fleeting (e.g., Leahy and Sweller, 2011), which can induce unnecessary cognitive load and prevent observers from receiving all the important aspects. Written vignettes allow for rereading and, thus, concentrating on the important information. On the other hand, videos can distract by presenting unimportant information such as the teacher's or the students' visible characteristics (Lowe, 2003). These distractions can be minimized by using written text. Recently, it has been demonstrated that written vignettes and videos are equally effective for assessing teachers' analytic skills (Friesen \& Kuntze, 2016). In the case of preservice teachers, written vignettes even improved the interpretation of classroom situations compared with videos (Schneider et al., 2016). With respect to these findings, we chose written vignettes. To ensure a satisfactory level of authenticity, we consulted experts in mathematics education who approved of the fictitious scenarios.

We used a set of six vignettes, each describing a mathematics lesson in which a student had some difficulties (see Table 1). In four of these vignettes, a student's utterances implied that he or she had the belief that mathematical ability is fixed. In addition, all vignettes contained other potential problems such as sub-optimal instruction or class-related problems. Thus, the preservice teachers could attribute the student's difficulties to the problematic belief about mathematical ability or to other factors. To disguise the focus of our study, we constructed two supplementary vignettes. These two "distractor vignettes" did not contain any beliefs about abilities. We further randomized the gender of the students described in the vignettes, thus controlling for gender influences on teachers' noticing. However, preservice teachers' responses did not differ with regard to the gender of the described student (all $p s>.17$ ).

The following example illustrates what the vignettes looked like: "Imagine you are teaching mathematics in the eighth grade. Your students are busy solving linear equations. From the corner of your eye, you see Jana folding up her exercise book and putting her head on the table. She looks frustrated. When you ask her what happened, she points at a page of her book where everything is crossed out and says, 'I just can't do it! It's wrong again! Whenever I put the number I've calculated into the first equation, I get different results! But it doesn't matter, I've always been bad at math, so what can I do?' You look at her solution and detect the mistake straight away: Jana subtracted instead of dividing. Such a mix-up often occurs in your class" (vignette b; translated from German). Note that the rationale of constructing these vignettes was to include student utterances related to mathematical beliefs but also to present other factors that can potentially be regarded as the source of the student's problem. Hence, the participating teachers could also ignore the belief aspect when analyzing the problem.

Participants read each vignette and answered three questions: (1) What main difficulty do you see? (2) What other difficulties do you see? (3) What would you do? We chose such general questions to support a natural process of noticing. By asking twice about difficulties, we aimed to obtain a wider range of responses. We did not judge whether belief-related problems were seen as a "main" or "other" difficulty, as we acknowledge that the different problems may be equally important. Instead, 
we analyzed whether beliefs were mentioned at all. In the example vignette, Jana's difficulties can be attributed to her belief that she cannot change being bad at mathematics, to problems with understanding the topic, to class-related problems such as an unproductive learning atmosphere, or to other student-related factors such as a general lack of motivation.

Table 1. Description of the classroom situations from the six vignettes and the students' belief-related utterance

Vignette Situation (and difficulties that could be noticed) Belief-related utterance

a Students in 5th grade work on computer-based tasks about fractions. One student complains about the difficult tasks and about the confusing pictures. The teacher encourages her/him to try again. (difficulties: ability belief, task design, teacher-student-interaction, etc.) Students in 8th grade solve linear equations. One student puts her/his head on the table and complains about the wrong results and her/his inability to do math. The teacher detects that she/ he mixed up subtraction and division.

(difficulties: ability belief, emotions, comprehension, etc.)

Students in 7th grade work on tasks about geometry (triangles). One students asks for a specific formula. The teacher invites her/ him to re-invent the formula by herself/ himself. The student denies. She/ he finds the formula in the book, but has trouble understanding it.

(difficulties: ability belief, memorization without comprehension, etc.)

Students in 6 th grade work in pairs on challenging puzzle tasks. Two students argue. The boy drags the worksheet to his side of the table and shields it from the girl. When the teacher asks him to put it back, the boy claims that girls cannot be good at math.

(difficulties: ability belief, social skills, instruction, grouping, etc.)

Students in 6th grade work on tasks with decimals. The teacher asks one student to present her solution. The girl's answer reveals her misconception about the addition of decimals. Another student giggles at her answer.

(difficulties: misconception, social skills, classroom interaction, etc.)
"I can't do math, no matter how hard I try"

"I've always been bad at math, so what can I do"

“Only scientists can really understand math"

“Girls just can't do math"

none (control)

none (control) task to continue with creating domino cards with functions and graphs. While some students start designing the cards, two boys build a house of cards. One girl paints all related cards in the same color.

(difficulties: extraneous behavior, instruction, classroom interaction, etc.) 
Intuitive theories about mathematical abilities. As a measure for intuitive theories, we constructed a sixitem questionnaire based on the Theories of Intelligence Scale (Dweck, 2000; Spinath \& Schöne, 2003). The original items were modified to accommodate 'mathematical abilities' instead of general intelligence. Furthermore, we distinguished between self-theories and other-theories, as suggested by Dweck (2000). We asked the participants for their theories about themselves (e.g., "My mathematical abilities can always change a lot") as well as about their students (e.g., "The mathematical abilities of students can always change a lot"). The participants rated the statements on a 5-point scale from 'strongly disagree' to 'strongly agree'. We formed two subscales for self-theory and student-theory, each consisting of three items. Higher scores represented an incremental theory; lower scores represented an entity theory. The scores for internal consistency reliabilities were satisfactory (selftheory: $\alpha=.66$; student-theory: $\alpha=.64$ ).

Procedure.

The participants first read the six vignettes and indicated the difficulties they perceived and what they would do. Afterwards they worked on questionnaires assessing their intuitive theories about mathematical abilities. The entire procedure was computer-based and took about 35 minutes.

Coding.

We analyzed participants' answers with content analysis and used specialized software for qualitative and mixed methods analysis (MAXQDA). In the first step, we analyzed all answers that described difficulties and teacher strategies, and coded whether they contained a student's belief about abilities or not. If an answer contained the belief, it was assigned a point. The answers that described main difficulties and 'other' difficulties - the first and the second question that we posed were aggregated for the analysis. Table 2 displays the coding scheme for difficulties; table 3 displays the coding scheme for teacher strategies. We calculated a noticing score by summing up the points for all four vignettes (i.e., a score of three means that a participant had referred to student beliefs in three vignettes). A maximum score of four would have been possible if a participant had mentioned beliefs in every vignette.

An independent assistant double-coded $20 \%$ of the answers, revealing high inter-rater reliability for noticing (ICC two-way mixed, not adjusted $=.80$ ) and for teacher strategies (ICC two-way mixed, not adjusted $=.82$ ). Disagreements between the raters were resolved through discussion. For instance, the raters discussed whether the mention of "stereotypes" was sufficient to get a point for noticing. They agreed on assigning a point only when stereotypes were related to mathematics learning (e.g., "the student holds the stereotype that girls cannot be good at math").

Table 2. Coding manual and interrater reliability for difficulties (vignettes a-d)

\begin{tabular}{|c|c|}
\hline Description & Examples (and counterexamples) \\
\hline $\begin{array}{l}\text { Vignette a: the difficulty refers to the } \\
\text { student's fixed belief about his/ her } \\
\text { mathematical abilities }\end{array}$ & $\begin{array}{l}\text { G. has a negative mathematical self-concept. } \\
\text { G. does not even try because he thinks that he } \\
\text { cannot understand math. }\end{array}$ \\
\hline & $\begin{array}{l}\text { G. does not like math. } \\
\text { The pictures distract G. from solving the task. }\end{array}$ \\
\hline $\begin{array}{l}\text { Vignette } b \text { : the difficulty refers to the } \\
\text { student's fixed belief about his/ her } \\
\text { mathematical abilities }\end{array}$ & $\begin{array}{l}\text { J. believes that she failed due to her low abilities. } \\
\text { J. is frustrated and thinks that she will never be } \\
\text { good at math. }\end{array}$ \\
\hline
\end{tabular}


Vignette c: the difficulty refers to the student's fixed belief that only scientists can understand mathematics

Vignette d: the difficulty refers to the student's fixed belief that girls are bad at mathematics

Maximum score

Interrater reliability (ICC two-way mixed, not adjusted)
J. is unmotivated and frustrated.

J. has a low self-esteem.

P. thinks that ordinary students cannot understand math.

Formulas are seen as something only experts can truly understand.

$P$. is not interested in math.

Students apply formulas without understanding them.

J. thinks that girls cannot think logically.

J. has the stereotype of women as being bad at math.

J. is prejudiced against girls.

The task is inappropriate for the different levels of achievement in this class.
4

.80

Table 3. Coding manual and interrater reliability for difficulties (vignettes a-d)

Description

Vignette a: the strategy refers to the student's fixed belief about his/ her mathematical abilities

Vignette $b$ : the strategy refers to the student's fixed belief about his/ her mathematical abilities

Vignette c: the strategy refers to the student's fixed belief that only scientists can understand mathematics
Examples (and counterexamples)

Points

I would give feedback that boosts his self-

1 concept in math.

I would offer support and show him that he can solve the task.

The teacher should motivate the student.

I would change the design of the tasks.

I would tell her that she underestimates her ability and that she can do math.

The teacher should explain that a mistake does not mean being bad at math.

I would comfort and motivate her.

I would repeat basic arithmetic operations with the entire class.

I would derive the formula with the students to 1 show them everybody can understand it.

I would ask myself why my students have the idea that math is only made for experts. 
Vignette d: the strategy refers to the student's fixed belief that girls are bad at mathematics

Interrater reliability (ICC two-way mixed, not adjusted)
I would derive the formula with the students.

The teacher should visualize the formula.

I would explain that mathematical ability has nothing to do with gender.

J. should work together with a boy who is bad at math to realize his assumption is wrong.

I would encourage him to explain the task to his team 0 partner.

The teacher should change the team partners.

In the second step, we looked at those answers containing beliefs in more detail and investigated whether the participants used theoretical concepts. If an answer contained a theoretical concept, we coded it as 'use of theoretical concepts'; if it did not, we coded it as 'no use of theoretical concepts'. Each concept was allocated to a separate subcategory. To avoid wrong inferences, we coded concepts only if they were named explicitly (not if they were vaguely described). Note that several theoretical concepts were coded in a single answer when appropriate.

Finally, we examined participants' ideas about what they would do when a student exhibits signs of a dysfunctional belief (i.e., answers to the third question that we posed). As we were interested in the kind of strategies the teachers developed, we inspected all answers exploratively, identifying two important dimensions. The first dimension was the strategy's timing. Some strategies referred to an application in the specific situation (short-term), whereas others referred to future lessons (long-term). The strategies differed further in their focus on either the teacher or the student as an active person. We thus defined the focus on the active person as a second dimension (teacher-focused vs. studentfocused). According to these two dimensions, we sorted all answers and identified one major strategy for each combination. One additional strategy referred to the specific situation as well as to future lessons and was therefore added as a mixed strategy. Overall, we defined five strategies (see results).

\section{Results}

Noticing student beliefs.

To address our first research question, we investigated whether preservice teachers noticed student beliefs about abilities in a classroom situation. We found that the mean score for noticing was low; on average, participants took notice of a problematic belief 1.23 times in all four vignettes (Min. $=0.00$; $M a x .=4.00 ; S D=1.17$ ). Figure 1 shows the frequencies of participants who mentioned student beliefs when describing the difficulties they saw and when developing strategies. The score frequencies further indicated that $35 \%$ of the participants did not mention beliefs at all in their answers, and $28 \%$ mentioned beliefs only once. 
Frequencies of participants who mentioned student beliefs

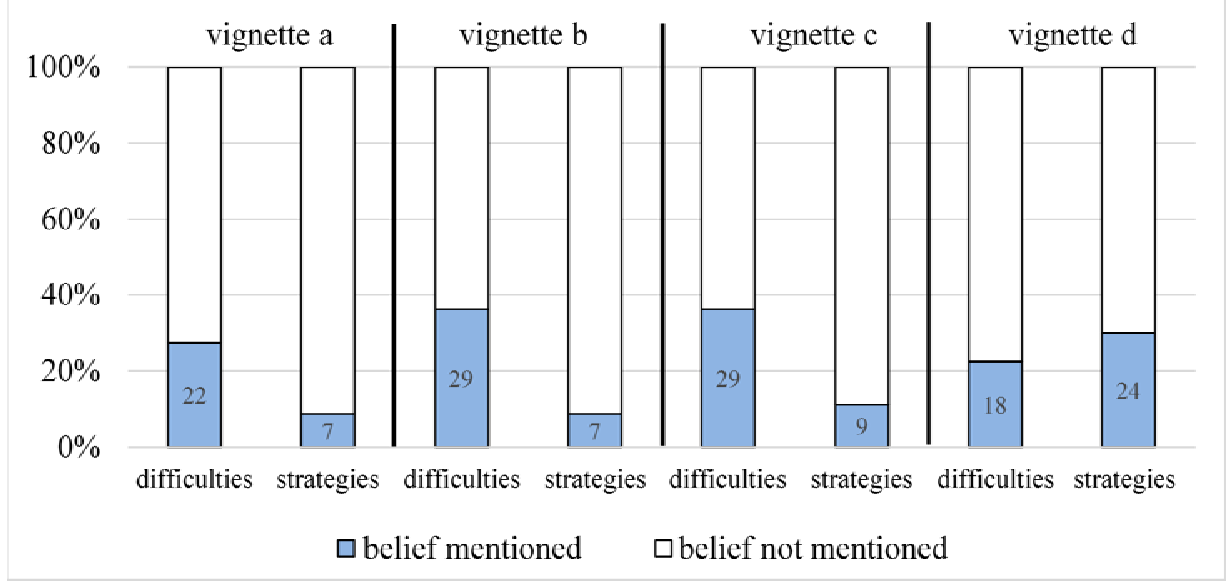

Figure 1. Frequencies of participants who mentioned student beliefs when describing difficulties and strategies $(N=80)$.

The analysis of the two distractor vignettes (vignette e and f) revealed that the participants had neither mentioned student beliefs as a difficulty, nor had they developed belief-related strategies (all $f$ $=0$ ). These frequencies were in contrast with the frequencies of belief-related answers in the four belief-vignettes (vignettes $\mathrm{a}, \mathrm{b}, \mathrm{c}$, and $\mathrm{d}$ ), which differed significantly from zero (all $p \mathrm{~s}<.008$ ). Hence, the belief-related vignettes were sensitive to assess how well preservice teachers noticed problematic beliefs.

Use of theoretical concepts when describing student beliefs.

With respect to our second research question, we investigated the extent to which the preservice teachers referred to theoretical concepts when they described beliefs. Of all the answers referring to beliefs, $63.7 \%$ contained no theoretical concepts, but provided rather "naïve" descriptions of the situation (e.g., "he thinks he can't do math" or "she is convinced only scientists understand math"). If participants used theoretical concepts, they referred to self-concept, attitudes, ability beliefs, or attribution as we expected. Additionally, participants applied suitable concepts that we had not considered beforehand, such as stereotypes, self-esteem, or self-fulfilling prophecy. We included all concepts in our analysis. Figure 2 illustrates the nine subcategories and frequencies. 


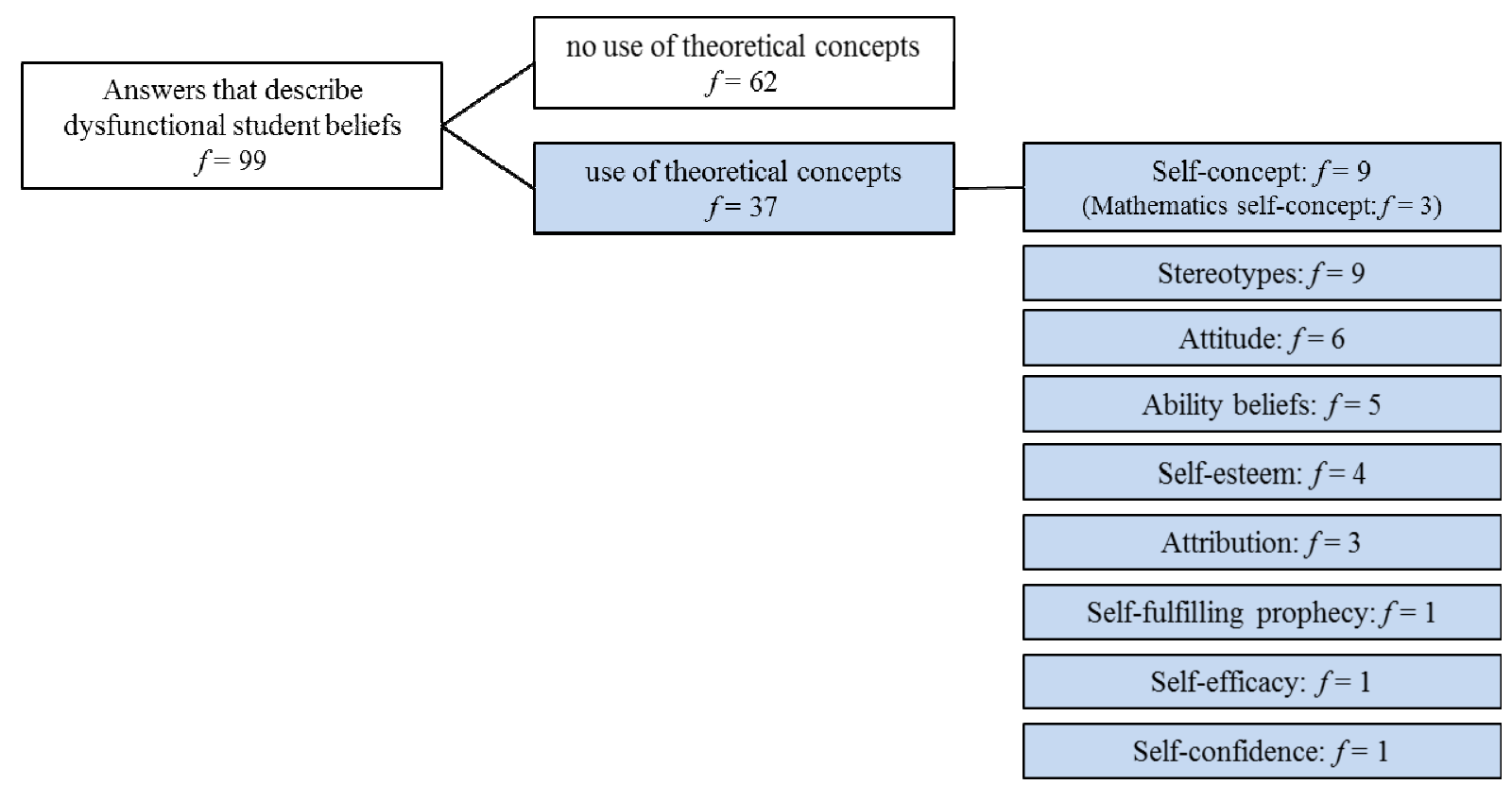

Figure 2. Theoretical concepts used by the participants when describing student beliefs $(n<80)$. Note that not every participant mentioned beliefs in their answers.

Strategies for dealing with dysfunctional student beliefs.

To address our third research question, we analyzed the kind of strategies the preservice teachers employed. Generally speaking, hardly any participants developed strategies that referred to students' beliefs. Figure 1 shows that frequencies were very low for vignettes a-c, but higher for vignette $d$. Hence, participants developed the most strategies for addressing the belief that 'girls just can't do math'. This result may be associated with our sample's high percentage of female participants. They may have disapproved of this gender-specific statement and found it necessary to intervene. As described above, we sorted all strategies according to the two dimensions 'timing' and 'focus on the active person' and identified five typical strategies:

Strategy 1: Question the dysfunctional belief by explanation (short-term, teacher-focused). Several participants suggested that the teacher questions the belief verbally and explains why it is unhelpful. Following this strategy, the teacher plays an active role, speaking to the student who has expressed the belief. For example, one participant suggested, "I would explain that not only great scientists can develop mathematical formulas, but also people like her." Another participant wrote, "I would make it clear to him that the ability to think logically has nothing to do with being a boy or a girl." The idea of questioning the belief via explanation is in line with what we know about effective belief-changing interventions: Mindset interventions usually start with an informative part in which the students are taught that cognitive abilities are malleable (for a review, see Yeager \& Walton, 2011). However, some ideas were inconsistent with research findings. For example, participants suggested "explaining that we all are good at something and not so good at other things" or that "everyone has strengths and weaknesses", which has overall dysfunctional consequences by supporting a fixed theory of ability (see Rattan et al., 2012).

Strategy 2: Question the belief by action (short-term, student-focused). Another strategy suggested by the preservice teachers was to question students' beliefs by making them act and, thereby, having them experience that their belief is inappropriate. Here, the teacher initiates the action, but puts the student in the active role. The following examples illustrate the kinds of actions the teachers suggested. In reaction to the belief that girls cannot do mathematics, participants had the idea to "give the student a 
seat next to a girl who is good at mathematics, so that he revises his stereotypical ideas," or to "make him prepare a presentation about famous female mathematicians." Such strategies are consistent with research findings, as belief-changing activities seem to be a crucial aspect of mindset interventions (Yeager \& Walton, 2011). In particular, giving a presentation may be a powerful means of selfpersuasion with regard to the "saying-is-believing" effect (Aronson, 1999). Another strategy that included an action to change the student's belief was the following: "I would work with him together on the next task to show him that he can actually do math." This suggestion is in line with general pedagogical knowledge (Woolfolk, 2012), as emphasizing students' progress can improve their ability beliefs. However, unintended negative effects of unrequested help are possible (Meyer, 1982).

Strategy 3: Promote a positive view of mistakes (short- and long-term, teacher-focused). This strategy addressed the students' negative attitude towards mistakes. The participants proposed promoting a more positive view by underlining the positive effects that mistakes can have. In so doing, the teacher was seen as the active person. As the strategy referred to both a specific situation and future lessons, we defined it as being short- and long-term. For example, one participant wrote, "I would tell him that mistakes like these do also happen to me," which refers to the specific situation. Another participant suggested "motivating the students by saying that mistakes can happen, but they do not mean that someone cannot do math." In this case, the participant addressed the entire class instead of just one student, giving the impression of a longer-term strategy.

Strategy 4: Give feedback to foster motivation (long-term, teacher-focused). Participants further suggested giving feedback that would foster the students' motivation by changing their ability beliefs. This suggestion was clearly teacher-based. In contrast to the previously described strategies, this strategy referred more to the student's general motivation than only to the specific situation. For example, one participant wrote, "I would give additional feedback to boost his self-esteem in mathematics." With regard to the deep impact that feedback can have on students' beliefs (Hattie \& Timperley, 2007), this strategy addresses a powerful tool for dealing with problematic beliefs. However, it remains unclear whether the participants considered the negative side effects that feedback can have (e.g., the paradoxical effects of praise for intelligence; Mueller and Dweck, 1998).

Strategy 5: Change dysfunctional attributions (long-term, student-focused). Finally, participants suggested changing dysfunctional attributions with the help of specific training. Although the teacher may support such training, the student must engage actively and work on his or her dysfunctional patterns of attribution. We therefore defined this idea as a student-focused strategy. Two examples illustrate how the participants described the strategy: "In case of a negative self-concept of ability, one should think about attribution training in the long run. This should support the belief that failures and difficulties occur due to changeable causes." "Attribution training seems to be useful. The student should acknowledge that he can influence his achievements in math and that they are not predetermined."

How noticing relates to academic progress, practical experience, and intuitive theories.

To investigate how noticing was associated with the preservice teachers' academic progress, their practical experience, and their intuitive theories about mathematical abilities, we carried out quantitative analysis. Regarding our fourth research question, we found that noticing was related neither to academic progress $(r=.04, p=.697)$, nor to practical experience $(r=-.03, p=.825)$. These correlations suggest that preservice teachers' ability to notice student beliefs does not improve automatically with growing academic or practical experience.

Regarding our fifth research question, we observed that noticing was positively related to preservice teachers' intuitive self-theories about mathematical abilities $(r=.30, p=.008)$. Holding an incremental theory about oneself - the belief that one's own abilities are malleable - is obviously a favorable 
condition for a teacher to notice belief-related problems in classroom situations. However, there was no significant relation between noticing and intuitive theories about students' mathematical abilities $(r=.15, p=.184)$.

\section{Discussion}

The purpose of this study was to analyze how preservice teachers notice, reason, and make decisions when they encounter students who believe that mathematical abilities are fixed. We found that the majority of the preservice teachers who participated in our study did not take notice of students' beliefs. If they did, they mainly reasoned using "naïve" descriptions like "he thinks he can't do math." Very few participants referred to theoretical concepts, whereby the most frequently used were self-concept, stereotypes, attitude, and ability beliefs. With respect to decision-making, few participants proposed any strategies to address problematic beliefs. These strategies differed in their timing (short- or long-term) as well as in their focus on either the teacher or student as an active person. Teacher-focused strategies included explanations that question the belief, the promotion of a positive view on mistakes, or feedback that could foster motivation. Student-focused strategies included an action that questions the belief or a change in dysfunctional attributions. While most of the strategies make sense from a professional point of view, others contradict empirical findings, for example by unintentionally supporting a fixed theory of ability.

The study provides first evidence about preservice teachers' abilities to react to problematic ability beliefs. We thus contribute to the literature by bridging research on students' beliefs about their mathematical abilities and research on teacher noticing. Specifically, we make the following contributions to the field: (1) we showed that most of the preservice teachers did not notice dysfunctional student beliefs. Considering the long-standing problems that such beliefs can cause, this finding is worrying and requires further attention. (2) We found that few teachers referred to theoretical concepts when describing beliefs. To our knowledge, this study is the first to report such problems in applying theoretical concepts to specific situations with respect to student beliefs. (3) We found that few teachers developed strategies for handling dysfunctional beliefs. Thus, the preservice teachers struggled with making instructional decisions about how to respond to the problematic belief. However, the strategies that were suggested mostly corresponded with findings from educational research. (4) Our data suggests that an incremental theory about mathematical abilities is positively related to noticing dysfunctional beliefs. This finding follows previous work on the relation between teacher beliefs and noticing, and confirms the positive impact of incremental beliefs for the specific noticing of problematic ability beliefs. In the following sections, we will discuss potential reasons for these results.

The rather low level of noticing, reasoning, and decision-making when facing students' beliefs may potentially be due to the low level of teaching experience the preservice teachers had. As mentioned earlier, practical experience plays a crucial role for explaining differences in teachers' professional vision. However, we assume that a general lack of experience cannot be the only reason for the rather poor results. If professional vision improved automatically with growing experience, preservice teachers with more practical experience would have shown a higher level of noticing than those with less experience. Yet we did not find noticing to be associated with academic progress or practical experience. This finding is in line with the research on the detection of students' mistakes, which does not improve with the increased practice (Krauss \& Brunner, 2011). Rather than assuming a general lack of experience, we propose three other aspects that may have caused the low level of professional vision.

First, the participants may have had little or no conceptual knowledge of ability beliefs. Closer examination of handbooks for mathematics teachers reveals that these books seldom address the issue 
of ability beliefs and their influence on students' motivation (e.g., Bruder et al., 2015; Lerman, 2014), which indicates that the relevance of ability beliefs tends to be underestimated in mathematics teacher education. Likewise, many of the preservice teachers who participated in our studies mentioned that they had "never learned anything about that," which may count as anecdotal evidence (this relates to online-comments and to comments we received throughout our local studies). Hence, we assume that some participants had too little conceptual knowledge to link with the specific classroom situation.

Second, the participants may have had conceptual knowledge of ability beliefs, but could not apply it. In this regard, the application of conceptual knowledge may have been the fundamental problem. Given that some of our participants applied suitable theoretical concepts, they seemed to possess a certain amount of knowledge. However, they may have had difficulty linking their abstract knowledge about beliefs with the specific classroom situation. This phenomenon is commonly referred to as inert knowledge (Renkl, Mandl, \& Gruber, 1996; Whitehead, 1929).

Third, the preservice teachers' own beliefs may have affected their noticing in that they failed to regard students' entity beliefs about abilities as a noteworthy difficulty. We found teacher beliefs, namely their intuitive theories regarding mathematical abilities, to be positively related to the ability to notice student beliefs. As we expected, holding an incremental theory was a favorable condition for noticing belief-related problems in classroom situations. Preservice teachers with an entity theory may not have seen a need to mention the dysfunctional belief as a difficulty, as the student's belief reflected their own 'correct' belief that mathematical ability is unchangeable. This finding is in line with previous research (Butler, 2000; Rattan et al., 2012) in which teachers attributed students' difficulties to different factors, depending on the intuitive theory they had.

Surprisingly, the correlation between noticing and intuitive theories was only significant for selftheory, compared with student-theory. As peoples' theories about their own abilities tend to resemble what they believe about others' abilities (Dweck, 2000), we did not expect such differences. However, we observed a general tendency towards incremental theories, which was even stronger concerning theories about students' abilities. In other words, participants had a more dynamic perspective regarding their students' abilities than their own. As the mean score for student-theory was close to the top end of the scale ( $M=4.03 ; S D=0.61$, on a five-point-scale), we assume a ceiling effect that may have caused the weak correlation in our study. A closer look at the descriptive data revealed another interesting aspect: some participants scored high on incremental theory, but low on noticing, whereas nobody scored low on incremental theory and high on noticing. Thus, an incremental self-theory seems to be a necessary but insufficient condition for noticing dysfunctional beliefs. For studenttheory, most scores were at the top of the scale and exhibited a rather undifferentiated pattern with respect to noticing.

In short, we assume that preservice teachers' professional vision was insufficient either because they had no conceptual knowledge of ability beliefs, failed to apply their conceptual knowledge, or did not regard students' entity beliefs about abilities as noteworthy difficulties. The latter may stem from intuitive theories the teachers hold, whereby the theory that mathematical abilities are malleable seems to be associated with better noticing of student beliefs.

Limitations and future studies.

Our study is limited in terms of its explanatory power, as it refers only to a small and nonrepresentative sample of preservice teachers. Thus, our data did not allow for comparisons between groups of different teaching expertise. A broader sample of preservice and in-service teachers could yield clearer results and may help to gain deeper insight into how experience shapes professional vision. Such an extended sample seems particularly interesting as practical experience could also have a negative indirect effect on teachers' noticing, mediated by their intuitive theories. This 
assumption is based on the interaction between experience, beliefs and professional vision: Research findings indicate that entity theories tend to increase over time (Georgiou, 2008). With respect to our finding that an incremental theory supports teachers' noticing of belief-related problems, growing entity theories may constitute an obstacle. Thus, further research is needed to investigate how experience shapes teachers' intuitive theories and their ability to notice student beliefs. Additionally, we propose asking the participants for specific experience with students who possess problematic beliefs, rather than measuring only general teaching experience.

Another limitation results from the measures used in this study. On one hand, the vignettes and the corresponding coding manuals were newly developed and need further validation. For this purpose, we aim at using the same vignettes in follow-up studies with different participants. Yet, the comparison between the control vignettes and the belief-related vignettes provides first evidence that the latter were sensitive to provoke belief-related answers. On the other hand, there was no direct measure of conceptual knowledge. We measured knowledge only indirectly, as we analyzed how participants described the difficulties they saw. If participants did not notice the belief, they, of course, did not write anything about ability beliefs. Yet they might have had the corresponding knowledge when asked directly. In addition, we coded theoretical concepts only when participants named them explicitly. Answers that referred to a theoretical concept without using the technical term were therefore not coded. Instructing participants to use technical terms in their answers may alleviate this problem; and a direct measure of conceptual knowledge would allow for stronger conclusions.

Furthermore, our study was limited to preservice mathematics teachers in Germany. Therefore, we do not know whether findings would generalize to other domains or cultures. On one hand, entity beliefs are found to be even stronger in the arts domains compared to, for instance, mathematics (Patterson, Kravchenko, Chen-Bouck, \& Kelley, 2016). On the other hand, intuitive theories about abilities are culturally shaped (e.g., Rattan, Savani, Naidu, \& Dweck, 2012). Citizens from Western societies tend to overestimate the influence of innate gifts, compared with, for instance, those from Asian cultures. Hence, further research could reveal whether these differences between domains and cultures result in differences regarding teachers' professional vision (see also Louie, 2018).

\section{Conclusion.}

Students' beliefs about their abilities have a huge impact on their motivation and learning. Especially in mathematics, the belief that either you are a "math person" or not is widespread and may lead to negative consequences. Thus, teachers should be capable of noticing such beliefs among their students and of acting appropriately. However, we found these abilities to be insufficient among preservice mathematics teachers. Only a few preservice teachers took notice of belief-related problems, described them professionally, or developed useful strategies. We assume that these results occurred due to a lack of conceptual knowledge as well as to problems putting this knowledge into practice. Furthermore, teachers' own beliefs shape their noticing of belief-related problems: an incremental theory about mathematical abilities is accompanied by being more aware of students' problematic beliefs about abilities.

As an implication for teacher education, it seems important to provide conceptual knowledge of students' beliefs and possible interventions. The present study shows that numerous theoretical concepts from both educational psychology and mathematics education serve these purposes. Thus, preservice teachers need not only to learn about these concepts; they also need support integrating different concepts to build coherent knowledge structures. Such an integration of knowledge may be supported with the help of specific instruction or prompts (e.g., Harr et al., 2015). In general, teachers should be made aware of both their students' beliefs and their own beliefs, in order to improve their skills in handling belief-related problems. 


\section{Acknowledgements}

This research was supported by grants from the German Federal Ministry of Education and Research (BMBF; 01JA1518A). The funding source was not involved in study design, data collection, analysis or interpretation, report writing, or submission for publication.

\section{References}

Aronson, E. (1999). The power of self-persuasion. American Psychologist, 54(11), 875-884. https://doi.org/10.1037/h0088188

Bandura, A. (1993). Perceived self-efficacy in cognitive development and functioning. Educational Psychologist, 28(2), 117-148. https://doi.org/10.1207/s15326985ep2802_3

Blackwell, L. S., Trzesniewski, K. H., \& Dweck, C. S. (2007). Implicit theories of intelligence predict achievement across an adolescent transition: A longitudinal study and an intervention. Child Development, 78(1), 246-263. https://doi.org/10.1111/j.1467-8624.2007.00995.x

Blömeke, S., Gustafsson, J.-E., \& Shavelson, R. J. (2015). Beyond dichotomies. Zeitschrift Für Psychologie, 223(1), 3-13. https://doi.org/10.1027/2151-2604/a000194

Blömeke, S., Hoth, J., Döhrmann, M., Busse, A., Kaiser, G., \& König, J. (2015). Teacher change during induction: Development of beginning primary teachers' knowledge, beliefs and performance. International Journal of Science and Mathematics Education, 13(2), 287-308. https://doi.org/10.1007/s10763-015-9619-4

Boaler, J. (2015). Mathematical mindsets: Unleashing students' potential through creative math, inspiring messages and innovative teaching. New York, NY: Wiley.

Borkowski, J. G., Weyhing, R. S., \& Carr, M. (1988). Effects of attributional retraining on strategy-based reading comprehension in learning-disabled students. Journal of Educational Psychology, 80(1), 46-53. https://doi.org/10.1037/0022-0663.80.1.46

Bruder, R., Hefendehl-Hebeker, L., Schmidt-Thieme, B., \& Weigand, H.-G. (2015). Handbuch der Mathematikdidaktik (2015th ed.). Berlin Heidelberg: Springer Spektrum.

Burkley, M., Parker, J., Paul Stermer, S., \& Burkley, E. (2010). Trait beliefs that make women vulnerable to math disengagement. Personality and Individual Differences, 48(2), 234-238. https://doi.org/10.1016/j.paid.2009.09.002

Burnette, J. L., O’Boyle, E. H., VanEpps, E. M., Pollack, J. M., \& Finkel, E. J. (2013). Mind-sets matter: A meta-analytic review of implicit theories and self-regulation. Psychological Bulletin, 139(3), 655-701. https://doi.org/10.1037/a0029531

Burnette, J. L., Russell, M. V., Hoyt, C. L., Orvidas, K., \& Widman, L. (2017). An online growth mindset intervention in a sample of rural adolescent girls. British Journal of Educational Psychology. https://doi.org/10.1111/bjep.12192

Butler, R. (2000). Making judgments about ability: the role of implicit theories of ability in moderating inferences from temporal and social comparison information. Journal of Personality and Social Psychology, 78(5), 965-978. https://doi.org/10.1037/0022-3514.78.5.965

Carter, K., Cushing, K., Sabers, D., Stein, P., \& Berliner, D. (1988). Expert-Novice Differences in Perceiving and Processing Visual Classroom Information. Journal of Teacher Education, 39(3), 25-31. https://doi.org/10.1177/002248718803900306

Cooper, S. (2009). Preservice teachers' analysis of children's work to make instructional decisions. School Science and Mathematics, 109(6), 355-362. https://doi.org/10.1111/j.1949-8594.2009.tb18105.x

Depaepe, F., Verschaffel, L., \& Kelchtermans, G. (2013). Pedagogical content knowledge: A systematic review of the way in which the concept has pervaded mathematics educational research. Teaching and Teacher Education, 34, 12-25. https://doi.org/10.1016/j.tate.2013.03.001

Dreher, A., \& Kuntze, S. (2014). Teachers' professional knowledge and noticing: the case of multiple representations in the mathematics classroom. Educational Studies in Mathematics, 88(1), 89-114. https://doi.org/10.1007/s10649-014-9577-8

Dweck, C. S. (2000). Self-theories: Their role in motivation, personality, and development. Philadelphia, PA: Psychology Press.

Friesen, M., \& Kuntze, S. (2016). Teacher students analyse texts, comics and video-based classroom vignettes regarding the use of representations - does format matter? In Proceedings of the 30th Annual Conference of the International Group for the Psychology of Mathematics Education (pp. 259-266). Szeged, Hungary.

Furner, J. M., \& Berman, B. T. (2003). Review of research: Math anxiety: Overcoming a major obstacle to the improvement of student math performance. Childhood Education, 79(3), 170-174. https://doi.org/10.1080/00094056.2003.10522220

Georgiou, S. N. (2008). Beliefs of experienced and novice teachers about achievement. Educational Psychology, 28(2), 119-131. https://doi.org/10.1080/01443410701468716

Grootenboer, P., Smith, T., \& Lowrie, T. (2006). Researching identity in mathematics education: The lay of the land. Identities, Cultures and Learning Spaces, 2, 612-615.

Grossman, P., Compton, C., Igra, D., Ronfeldt, M., Shahan, E., \& Williamson, P. (2009). Teaching practice: A cross-professional perspective. Teachers College Record, 111(9), 2055-2100.

Hand, V. (2012). Seeing culture and power in mathematical learning: Toward a model of equitable instruction. Educational Studies in Mathematics, 80(1-2), 233-247. https://doi.org/10.1007/s10649-012-9387-9

Harr, N., Eichler, A., \& Renkl, A. (2015). Integrated learning: ways of fostering the applicability of teachers' pedagogical and psychological knowledge. Educational Psychology, 738. https://doi.org/10.3389/fpsyg.2015.00738

Hattie, J., \& Timperley, H. (2007). The power of feedback. Review of Educational Research, 77(1), 81-112. https://doi.org/10.3102/003465430298487

Jacobs, V. R., Lamb, L. L. C., \& Philipp, R. A. (2010). Professional noticing of children's mathematical thinking. Journal for Research in Mathematics Education, 41(2), 169-202. 
Jonsson, A.-C., Beach, D., Korp, H., \& Erlandson, P. (2012). Teachers' implicit theories of intelligence: influences from different disciplines and scientific theories. European Journal of Teacher Education, 35(4), 387-400. https://doi.org/10.1080/02619768.2012.662636

Kaiser, G., Busse, A., Hoth, J., König, J., \& Blömeke, S. (2015). About the complexities of video-based assessments: Theoretical and methodological approaches to overcoming shortcomings of research on teachers' competence. International Journal of Science and Mathematics Education, 13(2), 369-387. https://doi.org/10.1007/s10763-015-9616-7

Kalinec-Craig, C. (2017). "Everything matters": Mexican-American prospective elementary teachers noticing issues of status and participation while learning to teach mathematics. In Teacher Noticing: Bridging and Broadening Perspectives, Contexts, and Frameworks (pp. 215-229). New York, NY: Springer. https://doi.org/10.1007/978-3-319-46753-5_13

Kelley, H. H. (1973). The processes of causal attribution. American Psychologist, 28(2), 107-128. https://doi.org/10.1037/h0034225

Kersting, N. B., Givvin, K. B., Thompson, B. J., Santagata, R., \& Stigler, J. W. (2012). Measuring usable knowledge: Teachers' analyses of mathematics classroom videos predict teaching quality and student learning. American Educational Research Journal, 49(3), 568-589. https://doi.org/10.3102/0002831212437853

König, J., \& Kramer, C. (2016). Teacher professional knowledge and classroom management: on the relation of general pedagogical knowledge (GPK) and classroom management expertise (CME). ZDM, 48(1-2), 139-151. https://doi.org/10.1007/s11858-015-0705-4

Krauss, S., \& Brunner, M. (2011). Schnelles Beurteilen von Schülerantworten: Ein Reaktionszeittest für Mathematiklehrer/innen. Journal für Mathematik-Didaktik, 32(2), 233. https://doi.org/10.1007/s13138-011-0029-z

Kuntze, S. (2012). Pedagogical content beliefs: Global, content domain-related and situation-specific components. Educational Studies in Mathematics, 79(2), 273-292. https://doi.org/10.1007/s10649-011-9347-9

Leahy, W., \& Sweller, J. (2011). Cognitive load theory, modality of presentation and the transient information effect. Applied Cognitive Psychology, 25(6), 943-951. https://doi.org/10.1002/acp.1787

Lee, M. Y., \& Cross Francis, D. (2017). Investigating the relationships among elementary teachers' perceptions of the use of students' thinking, their professional noticing skills, and their teaching practices. The Journal of Mathematical Behavior. https://doi.org/10.1016/j.jmathb.2017.11.007

Lerman, S. (Ed.). (2014). Encyclopedia of mathematics education. Dordrecht: Springer.

Louie, N. L. (2017). Culture and ideology in mathematics teacher noticing. Educational Studies in Mathematics, 1-15. https://doi.org/10.1007/s10649-017-9775-2

Louie, N. L. (2018). Culture and ideology in mathematics teacher noticing. Educational Studies in Mathematics, 97(1), 55-69. https://doi.org/10.1007/s10649-017-9775-2

Lowe, R. K. (2003). Animation and learning: Selective processing of information in dynamic graphics. Learning and Instruction, 13(2), 157-176. https://doi.org/10.1016/S0959-4752(02)00018-X

Marsh, H. W. (1990). A multidimensional, hierarchical model of self-concept: Theoretical and empirical justification. Educational Psychology Review, 2(2), 77-172. https://doi.org/10.1007/BF01322177

Marsh, H. W., \& Craven, R. (1997). Academic self-concept: Beyond the dustbowl. In G. D. Phye (Ed.), Handbook of classroom assessment: Learning, achievement, and adjustment. San Diego, CA: Academic Press.

Martino, P. D., \& Zan, R. (2010). 'Me and maths': Towards a definition of attitude grounded on students' narratives. Journal of Mathematics Teacher Education, 13(1), 27-48. https://doi.org/10.1007/s10857-009-9134-z

Meschede, N., Fiebranz, A., Möller, K., \& Steffensky, M. (2017). Teachers' professional vision, pedagogical content knowledge and beliefs: On its relation and differences between pre-service and in-service teachers. Teaching and Teacher Education, 66, 158-170. https://doi.org/10.1016/j.tate.2017.04.010

Meyer, W.-U. (1982). Indirect communications about perceived ability estimates. Journal of Educational Psychology, 74(6), 888897. https://doi.org/10.1037/0022-0663.74.6.888

Mueller, C. M., \& Dweck, C. S. (1998). Praise for intelligence can undermine children's motivation and performance. Journal of Personality and Social Psychology, 75(1), 33-52. https://doi.org/http://dx.doi.org/10.1037/0022-3514.75.1.33

OECD. (2013). PISA 2012 Results: Ready to learn. Students' engagement, drive and self-beliefs. Paris: OECD Publishing.

Pankow, L., Kaiser, G., Busse, A., König, J., Blömeke, S., Hoth, J., \& Döhrmann, M. (2016). Early career teachers' ability to focus on typical students errors in relation to the complexity of a mathematical topic. ZDM, 48(1-2), 55-67. https://doi.org/10.1007/s11858-016-0763-2

Patterson, M. M., Kravchenko, N., Chen-Bouck, L., \& Kelley, J. A. (2016). General and domain-specific beliefs about intelligence, ability, and effort among preservice and practicing teachers. Teaching and Teacher Education, 59, 180-190. https://doi.org/10.1016/j.tate.2016.06.004

Rattan, A., Good, C., \& Dweck, C. S. (2012). “It's ok - Not everyone can be good at math": Instructors with an entity theory comfort (and demotivate) students. Journal of Experimental Social Psychology, 48(3), 731-737. https://doi.org/10.1016/j.jesp.2011.12.012

Rattan, A., Savani, K., Naidu, N. V. R., \& Dweck, C. S. (2012). Can everyone become highly intelligent? Cultural differences in and societal consequences of beliefs about the universal potential for intelligence. Journal of Personality and Social Psychology, 103(5), 787-803. https://doi.org/10.1037/a0029263

Renkl, A., Mandl, H., \& Gruber, H. (1996). Inert knowledge: Analyses and remedies. Educational Psychologist, 31(2), $115-121$. https://doi.org/10.1207/s15326985ep3102_3

Saylan, A., Armagan, F. Ö., \& Bektas, O. (2016). The Relationship between Pre-Service Science Teachers' Epistemological Beliefs and Preferences for Creating a Constructivist Learning Environment. European Journal of Science and Mathematics Education, 4(2), 251-267. 
Schmidt, J. A., Shumow, L., \& Kackar-Cam, H. Z. (2017). Does Mindset Intervention Predict Students' Daily Experience in Classrooms? A Comparison of Seventh and Ninth Graders' Trajectories. Journal of Youth and Adolescence, 46(3), 582-602. https://doi.org/10.1007/s10964-016-0489-z

Schneider, J., Bohl, T., Kleinknecht, M., Rehm, M., Kuntze, S., \& Syring, M. (2016). Unterricht analysieren und reflektieren mit unterschiedlichen Fallmedien: Ist Video wirklich besser als Text? Unterrichtswissenschaft, 44(4), 474-489.

Schoenfeld, A. H. (1988). When good teaching leads to bad results: The disasters of "well-taught" mathematics courses. Educational Psychologist, 23(2), 145-166. https://doi.org/http://dx.doi.org/10.1207/s15326985ep2302_5

Seidel, T., \& Prenzel, M. (2007). Wie Lehrpersonen Unterricht wahrnehmen und einschätzen - Erfassung pädagogischpsychologischer Kompetenzen mit Videosequenzen. In M. Prenzel, I. Gogolin, \& H.-H. Krüger (Eds.), Kompetenzdiagnostik (pp. 201-216). Wiesbaden: VS Verlag für Sozialwissenschaften.

Seidel, T., \& Stürmer, K. (2014). Modeling and measuring the structure of professional vision in preservice teachers. American Educational Research Journal, 51(4), 739-771. https://doi.org/10.3102/0002831214531321

Shavelson, R. J., Hubner, J. J., \& Stanton, G. C. (1976). Self-concept: Validation of construct interpretations. Review of Educational Research, 46(3), 407-441. https://doi.org/10.3102/00346543046003407

Sherin, M. G., \& van Es, E. A. (2009). Effects of video club participation on teachers' professional vision. Journal of Teacher Education, 60(1), 20-37. https://doi.org/10.1177/0022487108328155

Shulman, L. S. (1986). Those who understand: Knowledge growth in teaching. Educational Researcher, 15(2), 4-14. https://doi.org/10.3102/0013189X015002004

Spinath, B., \& Schöne. (2003). Subjektive Überzeugungen zu Bedingungen von Erfolg in Lern- und Leistungskontexten und deren Erfassung. In J. Stiensmeier-Pelster \& F. Rheinberg (Eds.), Diagnostik von Motivation und Selbstkonzept (pp. 15-27). Göttingen: Hogrefe.

Stahnke, R., Schueler, S., \& Roesken-Winter, B. (2016). Teachers' perception, interpretation, and decision-making: A systematic review of empirical mathematics education research. ZDM, 48(1-2), 1-27. https://doi.org/10.1007/s11858-016-0775-y

Teuscher, D., Leatham, K. R., \& Peterson, B. E. (2017). From a Framework to a Lens: Learning to Notice Student Mathematical Thinking. In Teacher Noticing: Bridging and Broadening Perspectives, Contexts, and Frameworks (pp. 31-48). Springer, Cham. https://doi.org/10.1007/978-3-319-46753-5_3

Tuijl, C. van, \& Molen, J. H. W. van der. (2015). Study choice and career development in STEM fields: An overview and integration of the research. International Journal of Technology and Design Education, 26(2), 159-183. https://doi.org/10.1007/s10798-015-9308-1

van Es, E. A., \& Sherin, M. G. (2002). Learning to notice: Scaffolding new teachers' interpretations of classroom interactions. Journal of Technology and Teacher Education, 10(4), 571-596.

Voss, T., Kunter, M., \& Baumert, J. (2011). Assessing teacher candidates' general pedagogical/psychological knowledge: Test construction and validation. Journal of Educational Psychology, 103(4), 952-969. https://doi.org/10.1037/a0025125

Wager, A. A. (2014). Noticing children's participation: Insights into teacher positionality toward equitable mathematics pedagogy. Journal for Research in Mathematics Education, 45(3), 312-350. https://doi.org/10.5951/jresematheduc.45.3.0312

Whitehead, A. N. (1929). The aims of education. New York, NY: Macmillan.

Wood, R., \& Bandura, A. (1989). Impact of conceptions of ability on self-regulatory mechanisms and complex decision making. Journal of Personality and Social Psychology, 56(3), 407-415. https://doi.org/10.1037/0022-3514.56.3.407

Woolfolk, A. (2012). Educational Psychology (12 edition). Boston: Pearson.

Yeager, D. S., \& Walton, G. M. (2011). Social-psychological interventions in education: They're not magic. Review of Educational Research, 81(2), 267-301. https://doi.org/10.3102/0034654311405999 